\title{
Paper
}

\section{Increase of Snow Compaction Density by Repeated Artificial Snow Consolidation Formation}

\author{
Minoru Ishiguro** \\ KYŌSUKE NAKASORA ${ }^{\dagger}$ \\ YOTSUMi YoshiI ${ }^{\dagger}$
}

\author{
Non-member, \\ Non-member, \\ Non-member,
}

\author{
KAZUKI DAN ${ }^{\dagger}$ \\ YŨTA MORINO ${ }^{\dagger}$ \\ TOSHIMASA CHAKI ${ }^{\dagger}$
}

Non-member
Non-member
Non-member

(Received March 27, 2020, revised July 6, 2020)

\begin{abstract}
A method to consolidate huge amounts of snow into large ice pieces has been investigated based on science viewpoints for supporting the maintenance of road infrastructure in winter [1]. This study investigated repeated artificial snow consolidation formation for increasing snow compaction density. Producing compacted snow having density exceeding $\rho=0.8 \mathrm{~g} \cdot \mathrm{cm}^{-3}$ is known to require axial formation pressure $p_{z}=3.0 \mathrm{MPa}$. A snow consolidation method by lower axial formation pressure has long been demanded because axial formation pressure of $p_{z}=3.0 \mathrm{MPa}$ is extremely high. At such pressures, snow consolidation pressure vessels break easily. This study examines means of achieving higher density snow compaction by repeated artificial snow consolidation formation process with lower axial formation pressure $p_{z}$. Especially, axial formation pressure $p_{z}$, back pressure on lateral wall $p_{b}$ and those stress relaxations, and mean normal stress of the material $\sigma_{m}$, von Mises stress $\sigma_{Y}$ and deviatoric stress $\sigma_{i i}{ }^{\prime}$ were evaluated for elucidating snow consolidation mechanisms. Results show that the snow was consolidated by forced downward compression formation, the material internal pressure was increased, and the material deviatoric stress $\sigma_{x}{ }^{\prime}, \sigma_{y}{ }^{\prime}$ and back pressure $p_{b}$ on the pressure vessel lateral wall were increased rapidly. Results indicate measures to improve and increase snow compaction density by repeated snow consolidation formation with lower axial formation pressure $p_{z}$. The snow was consolidated by repeated artificial snow consolidation with the number of snow compaction processes $N=5$ time and $p_{z}=1.0 \mathrm{MPa}$.
\end{abstract}

Keywords: Deviatoric stress, Lévy-Mises assumption, Mean normal stress, Stress relaxation, von Mises stress,

\section{Introduction}

Recent labour shortages attributable to depopulation have become an important social issue in Japan [1]. In fact, labour shortages for snow removal work have been become a chronic social issue in snowy regions. In earlier reports, a high-speed snow compressor machine (HSSC) was investigated for assisting human power snow removal during disposal work. In those earlier studies, some fundamental artificial snow consolidation formation was done to produce snow consolidation properties for designing HSSC pressure vessels. Snow consolidation properties are known to be affected by the consolidation pressure vessel shape ratio. Therefore, axial formation pressure $p_{z}$ greater than $p_{z}=3.0$ $\mathrm{MPa}$ is used, which can easily break snow consolidation pressure vessels. The choice of snow consolidation pressure vessel shape ratios is important to obtain higher snow compaction density safely. Furthermore, back pressure on the lateral wall of the snow consolidation pressure vessel was recently discovered to occur only around the snow consolidation pressure vessel bottom. The back pressure is distributed heterogeneously along the height direction of the

\footnotetext{
* Corresponding: mishiguro@nc-toyama.ac.jp

† National Institute of Technology, Toyama College

Hongo 13, Toyama-shi, Toyama, Japan 939-8045
}

pressure vessel. However, the result represents a different trend from that of results found for natural snow consolidation [2] [3]. Those natural snow consolidation investigations demonstrated that the lateral back pressure was distributed uniformly along the height direction of the pressure vessel, and that the value of back pressure was the same value as that of axial formation pressure. A reason for the difference of back pressure distribution between artificial and natural snow consolidation was inferred as the difference of pressure vessel ratio and formation strain rate $\dot{\varepsilon}$. Furthermore, strain rate $\varepsilon$ at artificial snow consolidation formation was higher by $10^{6} \sim 10^{8}$ times than that of natural snow consolidation [1] [3]. However, in fact, little is known about the reason for the occurrence of those lateral back pressure distribution difference. Therefore, more detailed investigations of the back pressure occurrence were performed for assessing back pressure effects on material internal stress conditions using stress analysis based on stress relaxation, mean normal stress $\sigma_{m}$, von Mises stress $\sigma_{Y}$, and deviatoric stress $\sigma_{i i}{ }^{\prime}$.

\section{High-speed Snow Consolidation Formation}

Several investigations have been made of assessing snow consolidation properties. Furthermore, the strain rate $\dot{\varepsilon}$ of deformation processes is known to be an extremely impor- 
tant factor affecting those experiments. For example, if the uniaxial compression test is performed by $\hat{\varepsilon} \leq 10^{-2} s^{-1}$, then the material shows ductile deformation, but if the test is performed by $\dot{\varepsilon}>10^{-2} s^{-1}$, then the material shows brittle deformation [4] [5]. In the reports described above, natural snow consolidation was performed at $\dot{\varepsilon} \leq 10^{-5} s^{-1}$ [2] [3]. An artificial snow consolidation and snow dynamics research was undertaken at $\varepsilon=10^{-2} s^{-1}$ under a brittle deformation region [1]. For example, snow avalanches [6] [8], impact compression properties of snow or ice [9] [13], dry ice extrusion process [14] were investigated. Recently, regarding the high strain rate deformation of those advanced science studies, the metrology method was enhanced. For example, research related to internal cracking, porosity deformation, porosity existence rates during dynamic uniaxial compression or consolidation processes have been investigated using in-situ high-speed cameras or X-ray computed tomography (CT) [15] [17]. Using those methods, one can observe internal porosity and evaluate the ratio at each cross-section. However, some scientific knowledge, such as the relation between the internal stress condition and porosity rate has remained unknown. As described herein, stress analyses were conducted to estimate internal stress conditions of snow-consolidating materials. Especially, repeated artificial snow consolidation formation using square crosssection pressure vessel was done for evaluating repeated formation effects on increase of snow compaction density $\rho$. In the experiment, axial formation pressure $p_{z}$, back pressure on lateral wall $p_{b}$ and those stress relaxations were measured. Furthermore, mean normal stress $\sigma_{m}$ and von Mises stress $\sigma_{Y}$ related to the stresses described above were calculated and evaluated to confirm the repeated formation effects on the interactions among artificial snow compaction density $\rho$ and those stresses. That experimental process and its resultant details are described hereinafter.

\section{Experiment Procedures of Repeated Snow Consoli- dation Formation}

For this study, for artificial snow consolidation formation, snow materials were compressed at constant velocity $v=$ $50 \mathrm{~mm} . \mathrm{min}^{-1}$ for strain rates $\dot{\varepsilon}=6.66 \cdot 10^{-3} \mathrm{~s}^{-1}-1.33$. $10^{-2} s^{-1}$. Here, the strain rates $\varepsilon$ were almost $10^{8}$ times higher than those of natural snow consolidation formation [1] [3]. In an earlier report, the authors [2] described that uniformly normal mean stress was observed along the height direction of the experiment apparatus. By contrast, in the artificial snow consolidation formation with multipoint pressure measurement, uniformly normal mean stress was not observed in the tests [1]. If anything, the normal mean stress occurred disproportionately along the height direction of the pressure vessel. The back pressure was measured mainly only around the pressure vessel bottom. Therefore, multipoint pressure sensors system were used in this study for more details assessing the material internal stress condition. A schematic illustration of square cross-section artificial snow consolidation pressure vessel is presented in Fig. 1. The pressure vessel was made from JIS-S45C steel. The tool has a square cross-section, with small pressure sen-

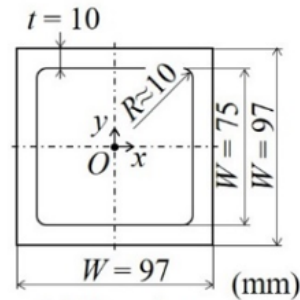

(a) Top view

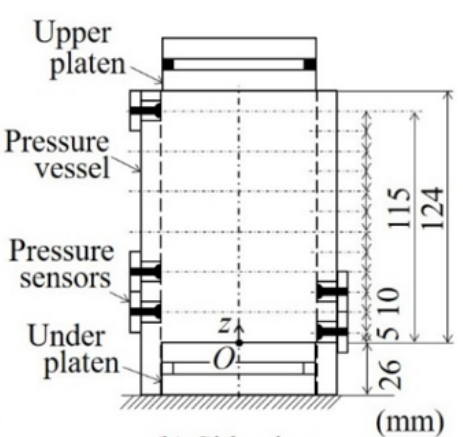

(b) Side view
Figure 1: Schematic illustration of square cross-section snow consolidation pressure vessel[1].

sors at 12 points along the lateral wall. The pressure sensors consist of some load cell sensors and a strain amplifier. Furthermore, a mechanical universal material testing machine with position and motion control software was used for testing. Furthermore, those tools were kept at temperatures of $T=0 \sim 7^{\circ} \mathrm{C}$ to avoid snow material melting during testing. Shaved ice resembling natural snow were used for all tests. Preliminary investigations confirmed that the shaved ice size is sufficient to obtain snow consolidation properties. It shows good agreement with result obtained using natural snow. Furthermore, the gap clearance between pressure vessel dies and platens was almost $0.5 \mathrm{~mm}$. Air in the material and pressure vessel dies can be released via the clearance.

Figure 2 presents a schematic illustration of snow consolidation test processes [1]. The snow consolidation pressure vessel and the under platen were set as shown in Fig.2(a). Then, after ice shaved ice were filled into the pressure vessel up to its upper rim, as shown in Fig.2(b), the movable upper platen was set on the tapped snow, as shown in Fig.2(c). The dies were closed by the upper and lower platens and the pressure vessel. Then the snow was artificially consolidated in those tools using several snow compaction processes $N=1 \sim 5$, as shown in Fig.2(d). The axial formation force, back pressure on the lateral wall of the pressure vessel and crosshead position were measured during the test with sampling frequency $f=100 \mathrm{~Hz}$. During the series of processes, after each consolidation formation, the cross-head position of the press machine was fixed. Stress relaxation was assessed after each process using a digital camera with sampling frequency $f=30 \mathrm{~Hz}$ [1]. The snow compaction density at an arbitrary crosshead position was evaluated by back calculation based on the recorded crosshead position data. Those tests were conducted using dimension ratios of $H / W=0.5,1.1$ and 1.7. Here, parameter $\mathrm{H}$ shows the initial filling snow height as shown in Fig.2(a); constant $W=75 \mathrm{~mm}$ represents the pressure vessel width. In this study, especially the result of the case of $H / W=1.7$ was reported because of the concept of huge amount of snow consolidation in short period of time. In this study, low axial formation pressure $p_{z_{-} \max }=1.0 \mathrm{MPa}$ was selected to the experiment for confirming the possibility of that the lower 


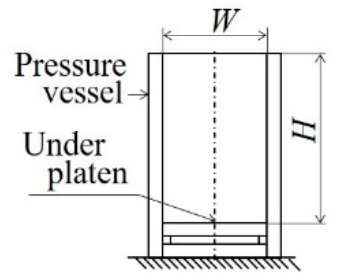

(a) Set up tool

Movable upper platen

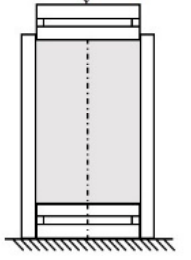

(c) Closing tools

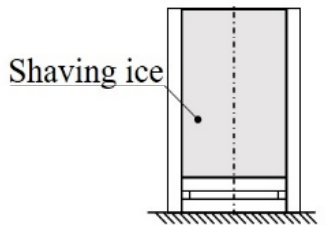

(b) Tapping snow

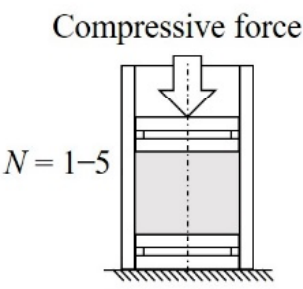

(d) Artificial snow consolidation
Figure 2: Schematic illustration of snow consolidation test processes[1].

formation pressure will obtain snow compaction density $\rho$ over $0.8 \mathrm{~g} \cdot \mathrm{cm}^{-3}$ or not. Earlier studies have demonstrated that snow compaction having $\rho>0.8 \mathrm{~g} \cdot \mathrm{cm}^{-3}$ by one stroke snow consolidation formation needs over $p_{z}=3.0 \mathrm{MPa}$ using hydraulic press machine. That high pressure can easily break the snow consolidation pressure vessel.

\section{Repeated Artificial Snow Consolidation Formation}

Increase of snow compaction density by repeated artificial snow consolidation formation was examined. Especially, the stress relaxation effect on increasing snow compaction density by the repeated formation was investigated. Relations among axial formation and back pressure and testing time for $p_{z_{-} \max }=1.0 \mathrm{MPa}$ and $H / W=1.7$ is shown in Fig. 3. That figure shows typical artificial snow consolidation properties behaviour to that described in an earlier report [1]. Back pressure occurred only for $S_{p}=5 \mathrm{~mm}$ around pressure vessel bottom at fix end. Furthermore, the maximum value of the back pressure decreased along with the increase of the number of snow compaction processes $N$. The total testing time was almost $170 \mathrm{~s}$, but each process was performed in a short time, except for $N=1$.

Then mean normal stress $\sigma_{m}$ was evaluated. Here, the mean normal stress $\sigma_{m}$ was calculated using Eq. 1 below. Here, $p_{z}$ is axial formation pressure; $p_{b}$ is the back pressure described above.

$$
\sigma_{m}=-\frac{p_{x}+p_{y}+p_{z}}{3}=-\frac{p_{b}+p_{b}+p_{z}}{3}
$$

Relations among mean normal stress and testing time for $S_{p}>5 \mathrm{~mm}$ and $S_{p}=5 \mathrm{~mm}$ for $p_{z_{-}} \max =1.0 \mathrm{MPa}$ and $H / W$ $=1.7$ are shown in Fig. 4. The expression " $S_{p}>5 \mathrm{~mm}$ " denotes the upper part place, except for $S_{p}=5 \mathrm{~mm}$, where there was no occurrence of the back pressure. For $S_{p}>$ $5 \mathrm{~mm}$, the snow was given almost uniform mean normal stress $\sigma_{m}=-0.3 \mathrm{MPa}$. However, for $S_{p}=5 \mathrm{~mm}$, the snow

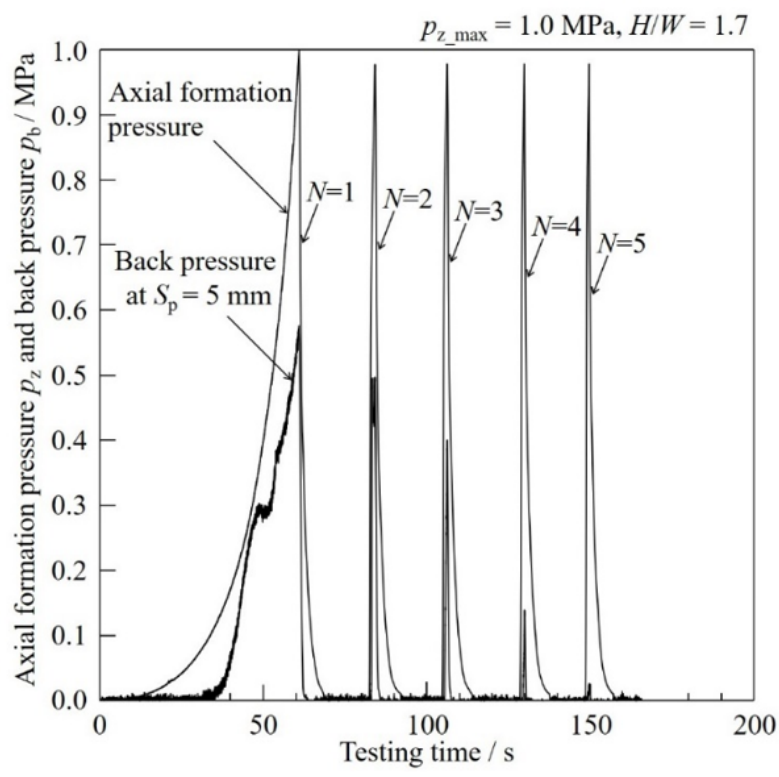

Figure 3: Relations among axial formation and back pressure during testing time for $p_{z_{-} \max }=1.0 \mathrm{MPa}$ and $H / W=$ 1.7 .

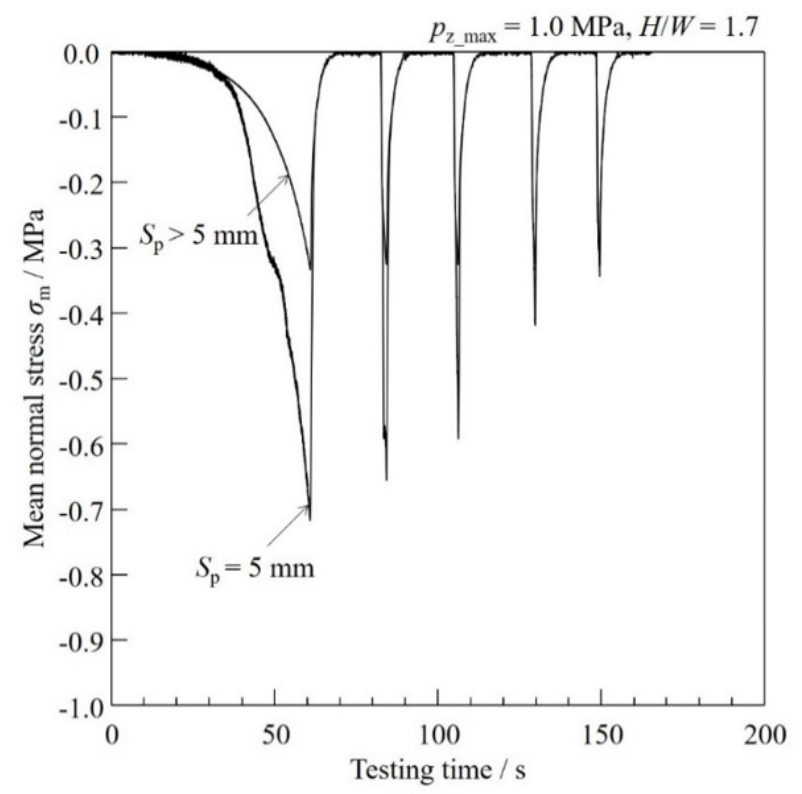

Figure 4: Relations among mean normal stress and testing time for $S_{p}>5 \mathrm{~mm}$ and $S_{p}=5 \mathrm{~mm}$ for $p_{z_{-} \max }=1.0 \mathrm{MPa}$ and $H / W=1.7$.

was given large compressive stress $\sigma_{m}=-0.7 \mathrm{MPa}$ at $N=$ 1. Then the absolute maximum value of that decreased concomitantly with increase the number of snow compaction process $N$. Furthermore, the snow was finally given mean normal stress $\sigma_{m} \approx-0.3 \mathrm{MPa}$ at $N=5$, which was the same value of that of $S_{p}>5 \mathrm{~mm}$ for $N=1 \sim 5$. At any rate, results show that the mean normal stress was not equal to axial formation pressure $p_{z_{-} \max }=1.0 \mathrm{MPa}$. The result was much different from the natural snow consolidation formation results [2] [3]. 


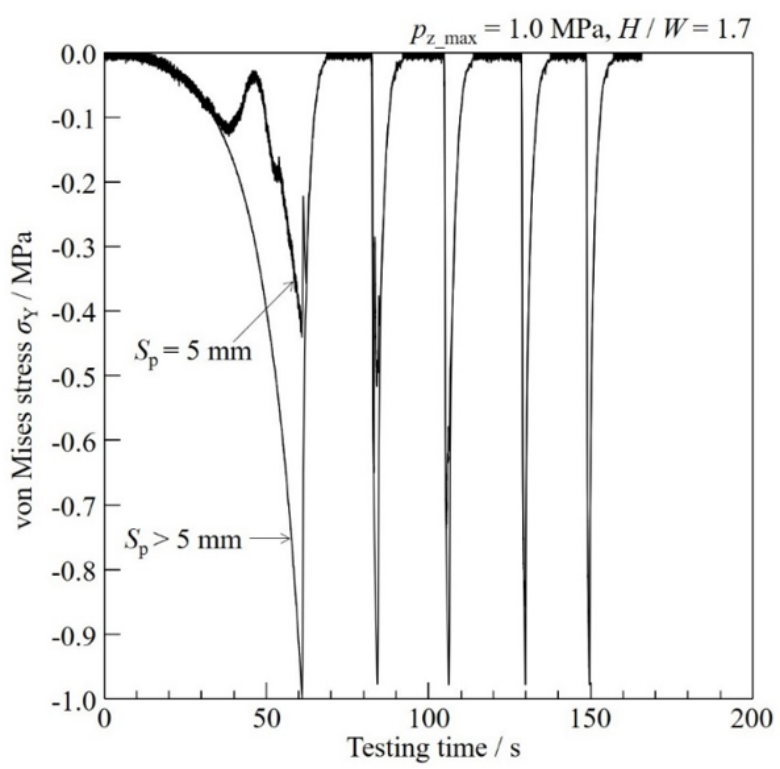

Figure 5: Relations among von Mises stress during testing time for $S_{p}>5 \mathrm{~mm}$ and $S_{p}=5 \mathrm{~mm}$ for $p_{z_{-} \max }=1.0 \mathrm{MPa}$ and $H / W=1.7$.

Then von Mises stress $\sigma_{Y}$ was evaluated. Here, $\sigma_{Y}$ denotes the von Mises stress, as given by following Eq. 2. Furthermore, $\sigma_{z}$ represents the $z$ direction axial stress, $\sigma_{z}=$ $p_{z}$; also, $\sigma_{x}$ and $\sigma_{Y}$ respectively denote the lateral direction stress of $\sigma_{x}=\sigma_{Y}=-p_{b}$,.

$$
\begin{array}{r}
\sigma_{Y}=\left[\frac{1}{2}\left\{\left(\sigma_{x}-\sigma_{y}\right)^{2}+\left(\sigma_{y}-\sigma_{z}\right)^{2}+\left(\sigma_{z}-\sigma_{x}\right)^{2}\right\}\right]^{\frac{1}{2}}, \\
\operatorname{sgn}\left\{\begin{array}{l}
+: \sigma_{m} \geq 0 \\
-: \sigma_{m}<0
\end{array}\right.
\end{array}
$$

Relations among von Mises stress and testing time for $S_{p}>5 \mathrm{~mm}$ and $S_{p}=5 \mathrm{~mm}$ for $p_{z_{-} \max }=1.0 \mathrm{MPa}$ and $H / W$ $=1.7$ is shown in Fig. 5. Here, $\sigma_{Y}$ for $S_{p}=5 \mathrm{~mm}$ decrease from $\sigma_{Y} \approx-0.4 \mathrm{MPa}$ down to $\sigma_{Y}=-1.0 \mathrm{MPa}$ along with the increase in the number of snow compaction processes $N$. Actually, $\sigma_{Y}$ for $S_{p}>5 \mathrm{~mm}$ was an almost constant value of $\sigma_{Y}=-1.0 \mathrm{MPa}$. The difference of von Mises stress occurrence is thought to derive from back pressure existence, as shown by Fig. 3. For $S_{p}>5 \mathrm{~mm}$, no lateral back pressure occurred. Therefore, the axial formation pressure directly becomes the driving force of the uniaxial snow compression and consolidation deformation force under $\sigma_{z}=-p_{z}$ and $\sigma_{x}=\sigma_{Y}=0 \mathrm{MPa}$. However, $\sigma_{Y}$ for $S_{p}=5 \mathrm{~mm}$, lateral back pressure was found. The value of $\sigma_{Y}$ was greater than $-1.0 \mathrm{MPa}$ of that of $S_{p}>5 \mathrm{~mm}$. Results demonstrated that von Mises stress $\sigma_{Y}$ of $S_{p}>5 \mathrm{~mm}$ was less than that of $S_{p}$ $=5 \mathrm{~mm}$. Moreover, snow of $S_{p}>5 \mathrm{~mm}$ tended to have a greater compressive deformation condition compared to the result of $S_{p}=5 \mathrm{~mm}$ by reason of back pressure existence.

In solid mechanics, generally von Mises stress $\sigma_{Y}$ and deviatoric stress $\sigma_{i i}{ }^{\prime}$ were considered for evaluating material deformation. The deviatoric stress $\sigma_{i i}{ }^{\prime}$ was evaluated for analyses of snow deformation behaviour, in an idea based

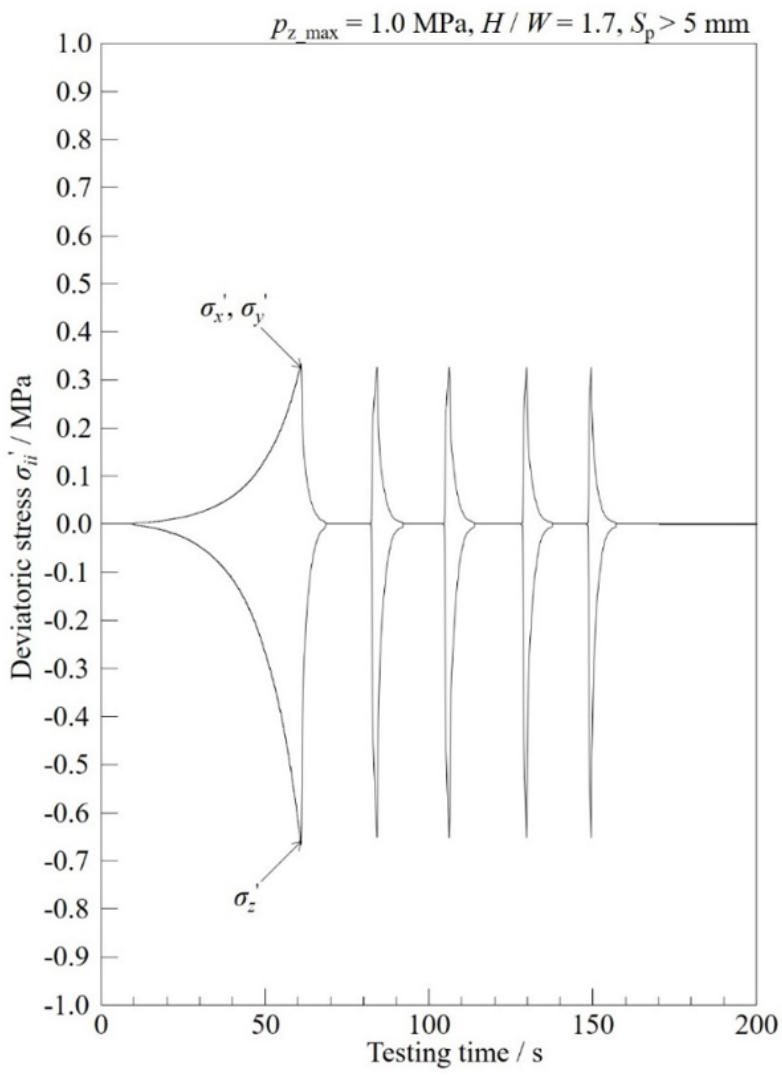

Figure 6: Relations among deviatoric stress and testing time for $p_{z_{-} \max }=1.0 \mathrm{MPa}$ and $H / W=1.7$ at $S_{p}>5 \mathrm{~mm}$.

on Lévy-Mises assumption. In the present study, adaptation of the theory was a bold assumption because the theory was generally adapted only under volume constancy and continuum material. Therefore, deviatoric stress evaluation is data used as a reference for consideration of snow deformation. The deviatoric stress $\sigma_{i i}{ }^{\prime}$ was defined by Eq. 3. Here, $\sigma_{i i}{ }^{\prime}$ and $\sigma_{i i}$ were stress components described by Einstein summation convention. In concrete, $\sigma_{i i}{ }^{\prime}$ were $\sigma_{x}{ }^{\prime}, \sigma_{y}{ }^{\prime}$ and $\sigma_{z}{ }^{\prime}$ under the assumption that the principle stress coordinate was matched to experiment coordinates.

$$
\sigma_{i i}^{\prime}=\sigma_{i i}-\sigma_{m}
$$

Relations among deviatoric stress and testing time for $p_{z_{-} \max }=1.0 \mathrm{MPa}$ and $H / W=1.7$ at $S_{p}>5 \mathrm{~mm}$ is presented in Fig. 6. Deviatoric stress $\sigma_{z}{ }^{\prime}$ for $S_{p}>5 \mathrm{~mm}$ had only negative values for $N=1 \sim 5$, the snow had been compressed during the process in the $z$ direction. Moreover $\sigma_{x}{ }^{\prime}$ and $\sigma_{y}{ }^{\prime}$ showed only positive values, meaning that the snow tended to bulge in the $x$ and $y$ directions during the process; in fact, it was constrained by the wall. Back pressure was not existent in that region because the volume of snow decreased, and because the volume constancy did not hold.

Relations among deviatoric stress and testing time for $p_{z_{-} \max }=1.0 \mathrm{MPa}$ and $H / W=1.7$ at $S_{p}=5 \mathrm{~mm}$ are shown in Fig. 7. In the snow consolidation process, it is thought that a compressive deformation state during processing was maintained by view point of $\sigma_{m}$ maintained a negative value 


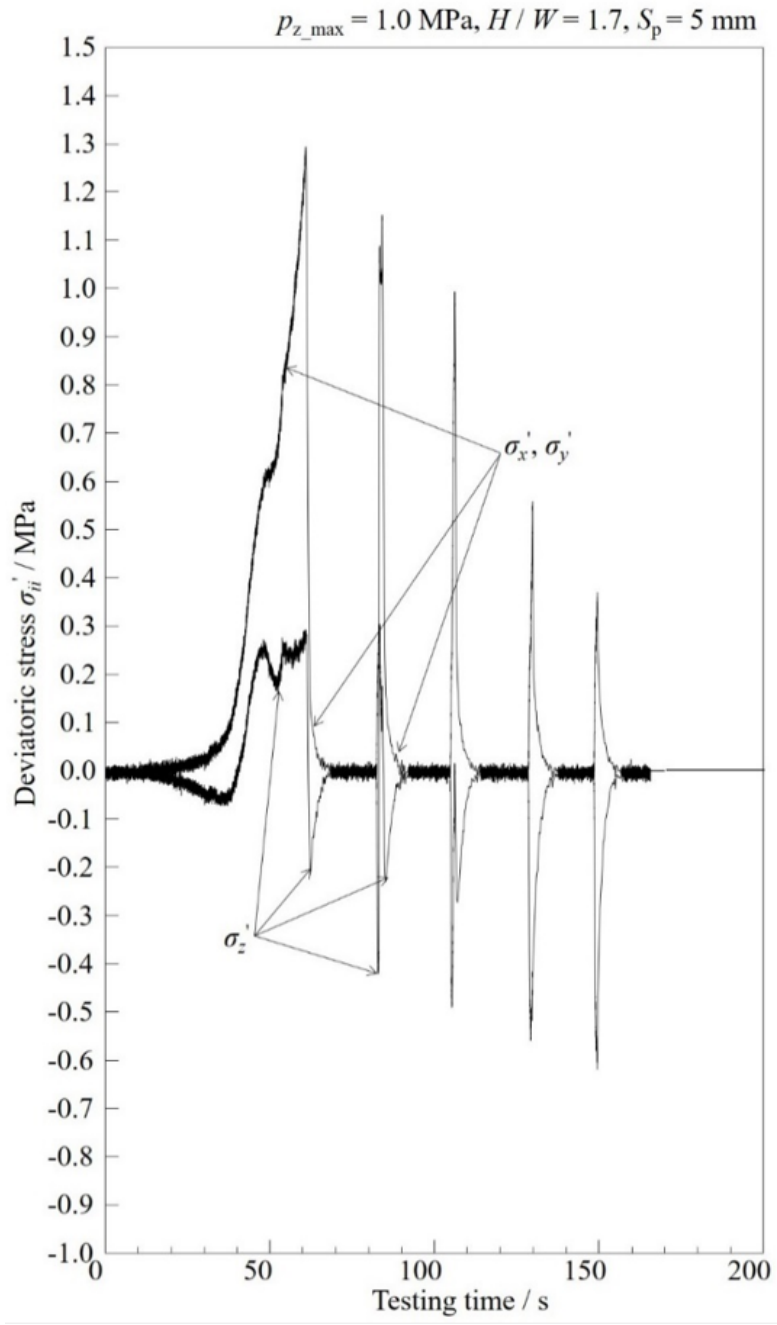

Figure 7: Relations among deviatoric stress and testing time for $p_{z_{-} \max }=1.0 \mathrm{MPa}$ and $H / W=1.7$ at $S_{p}=5 \mathrm{~mm}$.

during the process, as shown by Fig. 4. However, in fact, the deviatoric stresses as not only shown in a compressive state during the process. Deviatoric stress $\sigma_{z}{ }^{\prime}$ showed both positive and negative values for processes for $N=1 \sim 3$, when snow tended to bulge or compress during the respective processes. Moreover $\sigma_{x}{ }^{\prime}$ and $\sigma_{y}{ }^{\prime}$ showed only plus values, indicating that the material tended to bulge during the process. However, in fact, deformation in directions $x$ and $y$ was constrained. Therefore, the snow was allowed to deform only in the $z$ direction because the upper platen was forced to move downward monotonically because of experimental condition. Therefore, the snow was apparently forced to consolidate and the internal pressure increased. Actually, $\sigma_{z}{ }^{\prime}$ showed oscillatory behaviour for $N=1 \sim 3$, but no such oscillatory behaviour was found for $N=4$ and 5. The oscillation might be related with the existence of internal gases. That point has been investigated. Moreover, perhaps it would be able to adapt Shima-Oyane assumption for predicting powder consolidation mechanisms including volume shrinkage based on the Lévy-Mises assumption for $N=4$ and 5 because $\sigma_{z}{ }^{\prime}$ was found to have only monotonically negative values [18] [19].

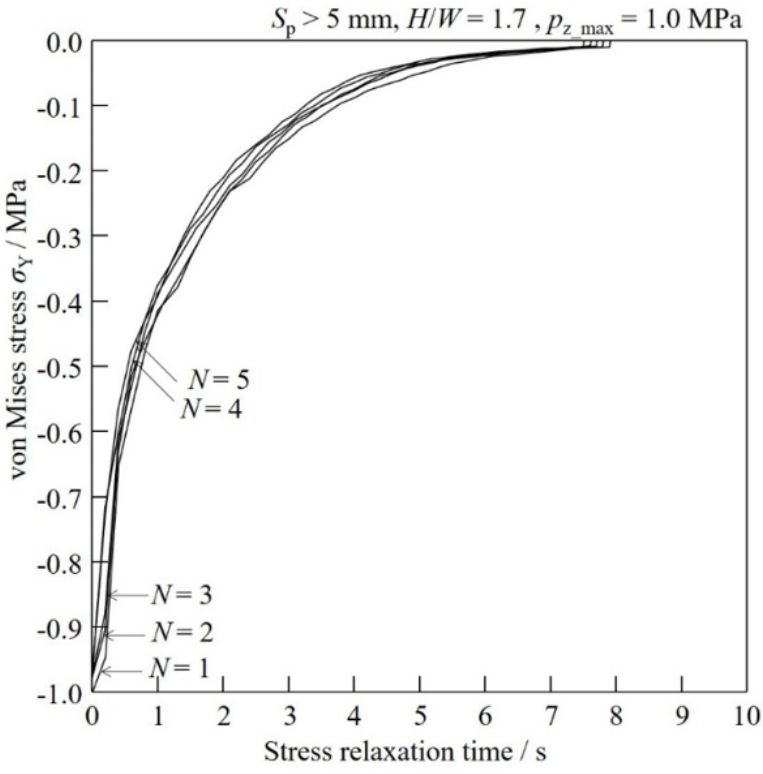

Figure 8: Relations between von Mises stress and stress relaxation time for $S_{p}>5 \mathrm{~mm}$ for $H / W=1.7, p_{z_{-} \max }=1.0$ MPa and $N=1 \sim 5$.

\section{Stress Relaxation during Snow Consolidation For- mation}

Stress relaxation was observed at each snow consolidation formation step, as shown by Fig. 3. The driving force of the stress relaxation is thought to be attributable to recrystallization of the snow, and a leak of internal higher-pressure gases during snow compaction. Furthermore, softening was thought to be a factor to increase the snow compaction density following each formation process. In this section, some details of the stress relaxation phenomena of snow compaction were investigated quantitatively and were discussed to assess the stress relaxation time.

The relations among von Mises stress and stress relaxation time for $S_{p}>5 \mathrm{~mm}$ for $H / W=1.7, p_{z_{-} \max }=1.0 \mathrm{MPa}$ and $N=1 \sim 5$ is shown in Fig. 8. The material showed damping behaviour for $N=1 \sim 5$. The snow material usually exhibited overdamping in a compressive deformation state. Furthermore, the material softened within $8.0 \mathrm{~s}$ after each snow compaction formation.

Relations for von Mises stress and stress relaxation time for $S_{p}=5 \mathrm{~mm}$ for $H / W=1.7, p_{z_{-} \max }=1.0 \mathrm{MPa}$ and $N=1 \sim 5$ are shown in Fig. 9. The result curve for $N$ $=1$ is shown as a dotted line to maintain distinctness of the result lines. The material showed damped oscillation behaviour for $N=1 \sim 3$. Those for $N=4$ and 5 showed damping behaviour. Furthermore, the maximum von Mises stress tended to delay of $t \approx 0.2 \mathrm{~s}$ compared with maximum axial formation pressure $p_{z}$ for $N=1 \sim 3$, but that delay disappeared for $N=4$ and 5 . The delay was thought to be the result of the drastically oscillating deviatoric stress for $N=1 \sim 3$. At present, the existence of internal gases and its effect on the oscillation behaviour have been investigated. Many unclear points remain, but results show clearly that the material properties changed during the re- 


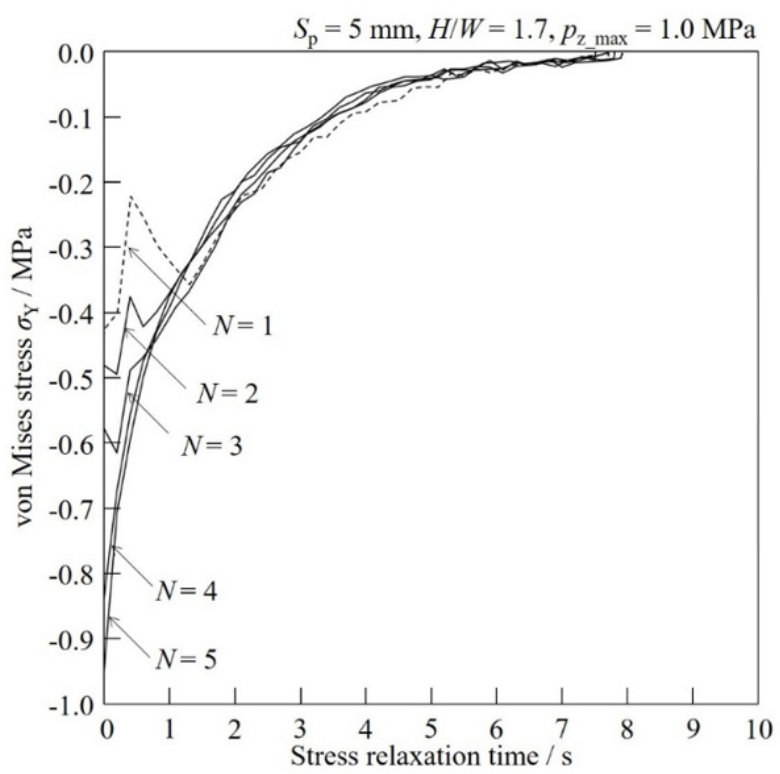

Figure 9: Relations among von Mises stress and stress relaxation time for $S_{p}=5 \mathrm{~mm}$ for $H / W=1.7, p_{z_{-} \max }=1.0$ $\mathrm{MPa}$ and $N=1 \sim 5$.

peated snow consolidation processes. Also, the material was almost invariably soft within $8.0 \mathrm{~s}$ after snow consolidation formation. Furthermore, the maximum value of $\sigma_{Y}$ decreased along with the increase of $N$. And it was expected that the snow compaction density was increased by the repeated snow consolidation processes.

Some differences are apparent between results obtained for $S_{p}>5 \mathrm{~mm}$ and $S_{p}=5 \mathrm{~mm}$. Both stress relaxation times were almost $8.0 \mathrm{~s}$. Results clarified that back pressure affects the stress relaxation phenomena, which show overdamping or damped oscillation behavior. Additional detailed observations using X-ray computed tomography are necessary for counting the trace internal gas volumes, and for confirming the plastic flow occurrence after release of internal gases.

\section{Increase of snow compaction Density through Re- peated Artificial Snow Consolidation Formation}

Relations among snow compaction density, axial formation pressure, and the number of snow compaction process $N$ for $H / W=1.7$ and $p_{z_{-} \max }=1.0 \mathrm{MPa}$ are shown in Fig. 10. The snow compaction densities for all $N$ show nonlinear behaviour along with the increase of axial formation pressure $p_{z}$, as shown in the figure. The snow compaction density increased markedly at $N=1$. Then the snow compaction density increased certainly for $N=2 \sim 5$, even though the increment of the density was very small.

The snow volume became almost half after final consolidation formation. The snow was converted into ice pieces by repeated formation, even though it had lower axial formation pressure. One reason for the increase of the snow compaction density at each deformation process is thought to be stress relaxation and material softening after each formation process, as described above.

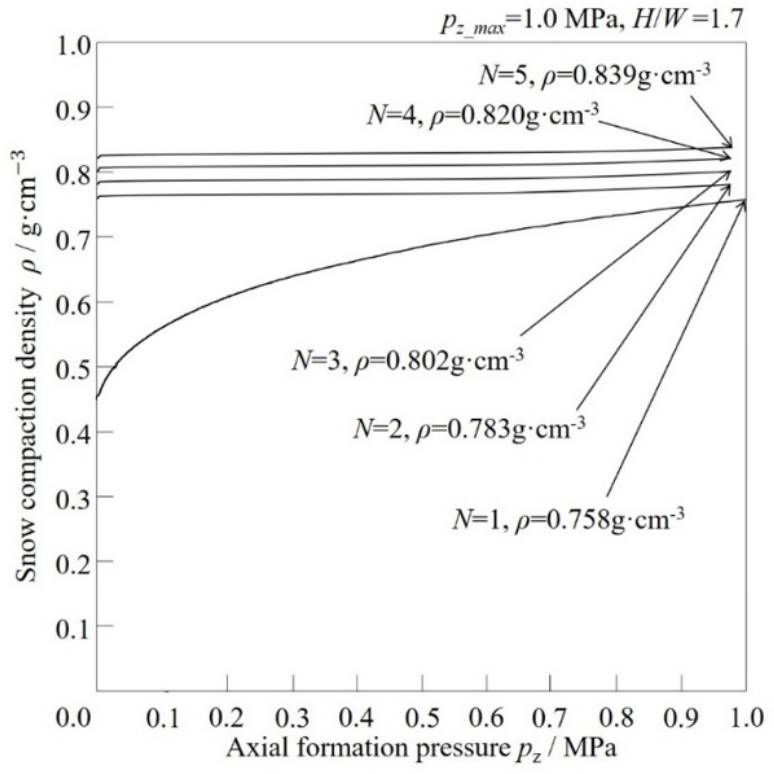

Figure 10: Relations among snow compaction density, axial formation pressure, and number of snow compaction processes $N$ for $H / W=1.7$ and $p_{z_{-} \max }=1.0 \mathrm{MPa}$.

Relations among snow compaction density and the number of snow compaction processes are shown in Fig. 11. The snow compaction density increased rapidly by the number of snow compaction processes $N=1$, the snow compaction density was saturated to $\rho \approx 0.800 \mathrm{~g} \cdot \mathrm{cm}^{-3}$ at $N$ $=3$. The snow volume became almost half after final repeated snow compaction processes $N=5$. Furthermore, the average snow compaction density became almost twice from $\rho_{\text {avg.ini. }}=0.431 \mathrm{~g} \cdot \mathrm{cm}^{-3}$ to $\rho_{\text {avg.fin. }}=0.844 \mathrm{~g} \cdot \mathrm{cm}^{-3}$. In comparison, the snow compaction density obtained by static consolidation condition using hand hydraulic press for $H / W=1.56$ and $p_{z-\max }=1.0 \mathrm{MP}$ was almost $\rho=0.550$ $\mathrm{g} \cdot \mathrm{cm}^{-3}[12]$. Therefore, one can readily infer that the dynamic snow consolidation process can achieve higher snow compaction density, even by lower axial compression formation pressure compared to those static consolidation processes.

\section{Conclusions}

For this study, axial formation pressure $p_{z}$, back pressure $p_{b}$ on snow consolidation pressure vessel lateral wall, and those stress relaxations were measured to support detailed investigations of the artificial snow consolidation properties on repeated snow consolidation formation. In addition, the mean normal stress $\sigma_{m}$, von Mises stress $\sigma_{Y}$ and deviatoric stress $\sigma_{i i}{ }^{\prime}$ were evaluated to confirm the repeated formation effect on the relation among snow compaction density $\rho$ and those stresses. Moreover, the following results were obtained.

(1) Back pressure occurred only for $S_{p}=5 \mathrm{~mm}$ around the pressure vessel bottom at fix end. The maximum value decreased along with the increase in the number of snow compaction processes $N$.

(2) Stress analysis results revealed that the snow material 


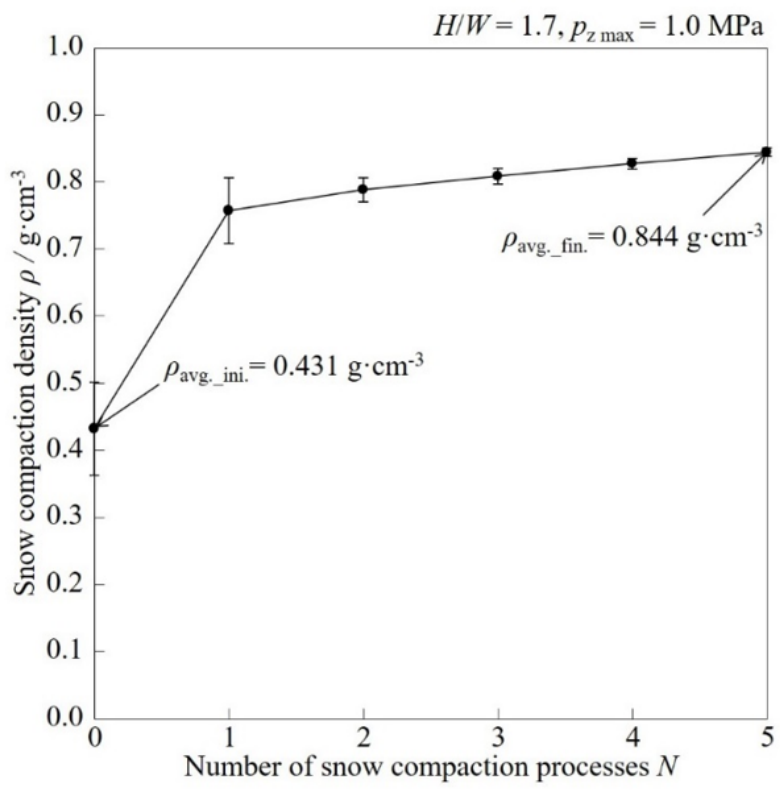

Figure 11: Relations among snow compaction density and the number of snow compaction processes.

for $S_{p}=5 \mathrm{~mm}$ was forced to consolidate, and that the internal pressure increased.

(3) The snow was overdamping compressive deformation state for $S_{p}>5 \mathrm{~mm}$. The snow was in an underdamping state for $S_{p}=5 \mathrm{~mm}$.

(4) The snow volume was almost halved after final repeated compaction processes at $N=5$. The snow compaction density became almost twice: from 0.431 to $0.844 \mathrm{~g} \cdot \mathrm{cm}^{-3}$. Snow was converted into ice pieces through repeated compaction processes, despite the lower axial formation pressure $p_{z_{-} \max }=1.0 \mathrm{MPa}$.

\section{Acknowledgment}

The authors thank all students and staff related to this project since 2010. Furthermore, this research received a grant from Foundation TAKEUCHI Education Scholarship: takeuchi2017-J-015 in 2017. We deeply appreciate that assistance.

\section{References}

[1] M. Ishiguro, H. Hayashi, Y. Yoshii, T. Tajiri, S. Kaneko and H. Okegawa, "Evaluation of Back Pressure on Lateral Wall of Square Cross Section Snow Compression Pressure Vessel", Journal of the Japanese Society for Experimental Mechanics, Vol.18, No.2, pp.130-140, 2018. DOI: $10.11395 / \mathrm{jjsem} .18 .130$

[2] N. Maeno and T. Ebinuma, "Pressure sintering of ice and its implication to the densification of snow at polar glaciers and ice sheets", The Journal of Physical Chemistry, Vol.87, No.21, pp.4103-4110, 1983. DOI: 10.1021/j100244a023
[3] T. Ebinuma and N. Maeno, "Experimental studies of densification and pressure-sintering of ice", Annals of Glaciology, Vol.6, pp.83-86, 1985. DOI: 10.3189/1985AoG6-1-83-86

[4] D. M. Cole, "Strain-rate and grain-size effects in ice", Journal of Glaciology, Vol.33, No.115, pp.274-280, 1987. DOI: $10.3189 / \mathrm{s} 0022143000008844$

[5] E. M. Schulson, "Brittle failure of ice", Engineering Fracture Mechanics, Vol.68, No.17-18, pp.1839-1887, 2001. DOI: 10.1016/S0013-7944(01)00037-6

[6] K. S. Carney, D. J. Benson, P. DuBois and R. Lee, "A phenomenological high strain rate model with failure for ice", International Journal of Solid and Structures, Vol.43, No.25-26, pp.7820-7839, 2006. DOI: $10.1016 / j . i j s o l s t r .2006 .04 .005$

[7] J. Heierli, P. Gumbsch and M. Zaiser, "Anticrack nucleatinon as triggering mechanism for snow slab avalanches", Science, Vol.321, No.5886, pp.240-243, 2008. DOI: $10.1126 /$ science. 1153948

[8] B. M. Chiaia, P. Cornetti and B. Frigo, "Triggering of dry snow slab avalanches:stress versus fracture mechanical approach", Cold Regions Science and Technology, Vol.53, No.2, pp.170-178, 2008. DOI: 10.1016/j.coldregions.2007.08.003

[9] J. Pernas-Sánchez, D. A. Pedroche, D. Varas, J. LópezPuente and R. Zaera, "Numerical modeling of ice behavior under high velocity impacts", International Journal of Solids and Structure, Vol.49, No.14, pp.1919-1927, 2012. DOI: 10.1016/j.jjsolstr.2012.03.038

[10] J. Lian, Q. Ouyang, X. Zhao, F. Liu, and C. Qi, "Uniaxial compressive strength and fracture mode of lake ice at moderate strain rates based on a digital speckle correlation method for deformation measurement", Applied Sciences, Vol.7, No.5, pp.1-28, 2017. DOI: 10.3390/app7050495

[11] C. Qi, J. Lian, Q. Ouyang and X. Zhao, "Dynamic compressive strength and failure of natural lake ice under moderate strain rates at near melting point temperature", Latin American Journal of Solids and Structures, Vol.14, No.9, pp.16691694, 2017. DOI: 10.1590/1679-78253907

[12] M. Ishiguro, K. Dan, S. Kaneko, Y. Yoshii, T. Tajiri and Y. Sakamoto, "Snow consolidation properties using mechanical press machine", Journal of Institute of Industrial Applications Engineers, Vol.7, No.3, pp.83-90, 2019. DOI: 10.12792/JIIAE.7.83

[13] Y. Wang, G. Chen, B. Wan, H. Lin and J. Zhang, "Behavior of innovative circular ice filled steel tubular stub columns under axial compression”, Construction and Building Materials, Vol.171, pp.680-689, 2018. DOI: 10.1016/j.conbuildmat.2018.03.208

[14] J. Córecki, I. Malujda, K. TalaŚ ka and D. Wojtkowiak, "Dry Ice Compaction in Piston Extrusion Process", Acta mechanica et automaticas, Vol.11, No.4, pp.313-316, 2017. DOI: 10.1515/ama-2017-0048

[15] A. Burr, C. Ballot, P. Lhuissier, P. Martinerie, C. L. Martin and A. Philip, "Pore morphology of polar firn around closure 
revealed by X-ray tomography", The Cryosphere, Vol.12, No.7, pp.2481-2500, 2018. DOI: 10.5194/tc-12-2481-2018

[16] K. L. Eppanapelli, F. Forsberg, J. Casselgren and H. Lycksam, "3D analysis of deformation and porosity of dry natural snow during compaction", Materials, Vol.12, No.6, pp.1-15, 2019. DOI: $10.3390 / \mathrm{ma} 12060850$

[17] M. Isakov, J. Lange, S. Kilchert and M. May, "In-Situ damage evaluation of pure ice under high rate compressive loading", Materials, Vol.12, No.8, pp.1-16, 2019. DOI: 10.3390/ma12081236

[18] S. Shima and M. Oyane, "Plasticity theory for porous metals", International Journal of Mechanical Sciences, Vol.18, No.6, pp.285-291, 1976. DOI: 10.1016/00207403(76)90030-8

[19] S. Shima and K. Mimura, "Densification behavior of ceramic powder", International Journal of Mechanical Sciences, Vol.28, No.1, pp.53-59, 1986. DOI: 10.1016/00207403(86)90007-X

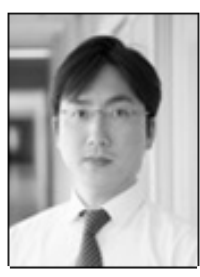

Minoru Ishiguro (Non-member) was born in Yamagata, Japan, 1980. He received the B. S. and M. S. degrees in Production System Engineering at 2002 and 2004, and the Ph. D. degree in Mechanical Structure System Engineer from Toyohashi University of Technology at 2007. From 2007 he has worked at Toyama National College of technology as Assistant Professor. Since 2010, he worked at National Institute of Technology (NIT), Toyama College. He was Lecturer since 2016-2019. He is presently Associate Professor since 2019. He is member of JSME, JSSI, JSDE and JSEM.

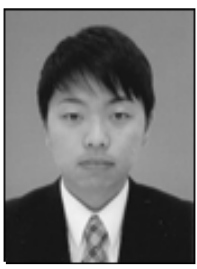

Kazuki Dan (Non-member) was born in Toyama, Japan, 1998. He is graduated student of Mechanical system Engineering in NIT, Toyama College at 2019. He received Associate degree in Mechanical System Engineering from NIT Toyama College at 2019. Since 2019, he has worekd at Finecs company limited.

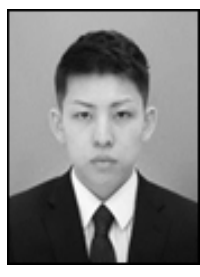

Kyōsuke Nakasora (Non-member) was born in Toyama, Japan, 1998. He is graduated student of Mechanical System Engineering in NIT, Toyama College at 2019. He received Associate degree in Mechanical System Engineering from NIT, Toyama College at 2019. He is enrolled in Advanced Course of ECO design Engineering at NIT Toyama College.

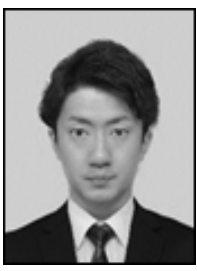

Yūta Morino (Non-member) was born in Toyama, Japan, 1998. He is graduated student of Mechanical System Engineering in NIT Toyama College at 2019. He received Associate degree in Mechanical System Engineering from NIT Toyama College at 2019. He is enrolled in Mechanical Engineering at Nagaoka University of Technology.

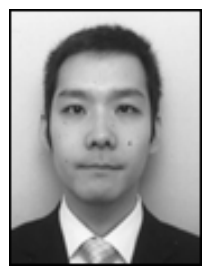

Yotsumi Yoshii (Non-member) received the B.S. and M.S. degrees in Image science from Chiba University in 1999 and 2001. He received the Ph.D. degree in Artificial systems science from Chiba University in 2004. From 2004 to 2005, he was a postdoctoral researcher at University of Fukui. From 2005 to 2010, he was an Assistant Professor at Toyama National College of Maritime Technology. Since 2010, he has been an Associate Professor at NIT, Toyama College. His current research interests include sensors, laser spectroscopy, and signal processing. He is a member of JSAP and IEEJ.

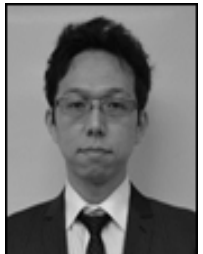

Toshimasa Chaki (Non-member) was born in Toyama, Japan, 1980. He graduated Hokuriku Polytechnic College at 2003. From 2003 to 2013, he had worked high precision mechanical processing company. Since 2013, he has worked at NIT Toyama College as high precision processing technical faculty at NIT Toyama College. 